\title{
Increased serum levels of brain-derived neurotropic factor during migraine attacks: a pilot study
}

\author{
Marco Túlio A. Tanure $\cdot$ Rodrigo S. Gomez • \\ Rubens Carlos L. Hurtado · Antônio L. Teixeira • \\ Renan Barros Domingues
}

Received: 19 May 2010/ Accepted: 4 June 2010/Published online: 17 June 2010

(C) Springer-Verlag 2010

\begin{abstract}
There is a growing body of evidence implicating inflammatory cytokines and brain-derived neurotropic factor (BDNF) in the generation of migraine pain. No previous study evaluated BNDF levels during migraine attacks and there are conflicting results regarding tumor necrosis factoralpha (TNF-alpha) serum levels. This study compared serum levels of TNF-alpha, soluble TNF receptors 1 and 2 (sTNF$\mathrm{R} 1$ and sTNF-R2), and BDNF during migraine attacks and in headache-free periods. Nine patients with episodic migraine were clinically evaluated during a migraine attack and in a headache-free period. Blood sample of each patient in both occasions was collected and all serum was submitted to TNFalpha, sTNF-R1, sTNF-R2, and BDNF determination by ELISA. There was no significant difference in the serum levels of TNF-alpha, sTNF-R1 and sTNF-R2 in migraine attack period and headache-free period. BDNF serum levels were significantly higher during migraine attack than in painfree period. This is the first report showing that BDNF serum levels increase during migraine attack. This reinforces the view that BDNF may be implicated in the physiopathology of migraine.
\end{abstract}

Keywords Migraine $\cdot$ Cytokines $\cdot$ TNF- $\alpha \cdot$ BDNF

\section{Introduction}

Migraine is a very common neurologic disorder [1]. The mechanisms involved in the generation of migraine attack

M. T. A. Tanure - R. S. Gomez - R. C. L. Hurtado ·

A. L. Teixeira $\cdot$ R. B. Domingues $(\bowtie)$

School of Health Sciences of Santa Casa de Misericórdia de Vitória, Vitória, Brazil

e-mail: contato@renandomingues.med.br are probably multifactorial and are not fully understood [2]. It has been proposed that neurogenic inflammation causes pain during migraine attack. The neurogenic inflammation is generated by the release of neuropeptides such as calcitonin gene-related peptide (CGRP) from trigeminal neurons terminals and leads to inflammation with the release of cytokines such as interleukin-6 (Il-6) and tumor necrosis factor-alpha (TNF- $\alpha$ ) [2]. Some studies demonstrated elevated levels of these cytokines in jugular vein during acute migraine attacks, however, there were discrepant results with respect to the determination of serum levels of cytokines in migraine patients [3-6].

Brain-derived neurotropic factor (BDNF) is a neurotrophin that has been implicated in the generation and modulation of pain [7]. Some studies have found that BDNF levels are altered in migraine patients when compared to controls [8]. No previous study evaluated BDNF serum levels during migraine attacks. Therefore, it is unknown whether there is any change in the serum level of BDNF during migraine attacks.

The aim of this study was to investigate the levels of TNF- $\alpha$, soluble TNF receptors 1 and 2 (sTNF-R1 and sTNF-R2), and BDNF during migraine attack and in headache-free period in adult patients with episodic migraine.

\section{Patients and methods}

Clinical evaluation

Nine patients with established diagnosis of episodic migraine without aura were included in this study. The patients were evaluated at the Hospital Madre Teresa, Belo Horizonte, Brazil. The diagnosis of migraine was done by a 
headache specialist according to the International Headache Criteria [9]. All patients signed informed consent form before inclusion in the study and this study was approved by the local ethics research committee. Age, gender, and time of migraine attacks history were recorded. The impact of migraine was evaluated with migraine disability assessment (MIDAS) and headache impact test (HIT) [10].

The patients were evaluated twice. The first evaluation was during a migraine attack when the patients sought medical attention. At this time the headache intensity was also evaluated by the visual analogue scale (VAS). The second evaluation was performed 1 week later if the patient reported to be completely pain free in the last $72 \mathrm{~h}$. In both evaluations blood samples were collected for the determination of serum markers.

\section{Measurement of TNF- $\alpha$, sTNF-R1, sTNF-R2} and BDNF

Blood was aseptically collected. Serum was separated within $30 \mathrm{~min}$ and the supernatant was stored at $-70^{\circ} \mathrm{C}$ until required. For analysis, samples were thawed. The concentration of TNF- $\alpha$, sTNF-R1, sTNF-R2 and BDNF in serum of migraine patients with and without pain was assessed by using sandwich ELISA kits (Highly Sensitive R\&D Systems, for TNF- $\alpha$ and Duo Set R\&D Systems Minneapolis, MN, USA, for sTNF-R1, sTNF-R2 and $\mathrm{BDNF}$ ). The detection limits for these assays were $0.5 \mathrm{pg} /$ $\mathrm{ml}$ for TNF- $\alpha$ and $5.0 \mathrm{pg} / \mathrm{ml}$ for sTNF-R1, sTNF-R2 and BDNF.

\section{Statistical analysis}

Wilcoxon signed-rank test was used for comparison of TNF- $\alpha$, sTNF-R1, sTNF-R2, and BDNF concentrations from the patients during the migraine attack and in the pain-free period. Spearman correlation test was used to evaluate correlation between age, time of migraine, MIDAS, HIT, and VAS with serum TNF- $\alpha$, sTNF-R1, sTNF-R2, and BDNF concentrations. All the calculations were performed using GraphPad Prism version 4.00 for Windows software (GraphPad Software Inc., San Diego, CA, USA). The level of significance was set at $P<0.05$.

\section{Results}

Eight of the nine patients were women. The mean age was $23.8 \pm 2.8$ mean \pm SD MIDAS and HIT scores were $39.5 \pm 44.8$ and $63.3 \pm 5.7$, respectively. The intensity of pain during migraine attack period ranged from 5 to 10 , the mean being $8.4 \pm 1.7$.
The comparison of TNF- $\alpha$, sTNF-R1, sTNF-R2 serum levels during migraine attack and during pain-free period are shown in Fig. 1. There was no significant difference in TNF- $\alpha$ (sum of signed ranks (W) -6.0), sTNF-R1 (sum of signed ranks (W) 15.0), sTNF-R2 (sum of signed ranks (W) $-17.0)$ levels between these two periods $(P>0.05)$.

The comparison of BDNF serum levels during migraine attack and during migraine-free period is shown in Fig. 1. BDNF serum levels were significantly increased during migraine attack period (sum of signed ranks (W) 43.0; $P=0.008)$.

Age, length of disease, MIDAS, HIT and VAS scores did not correlate with TNF- $\alpha$, sTNF-R1 and sTNF-R2 levels during migraine attack or in the headache-free period. Serum levels of BDNF were inversely correlated with the headache $(r=0.6325, P=0.043)$.

\section{Discussion}

Cytokines are pain mediators and it is believed that they are implicated in neurovascular inflammation resulting in migraine pain [2]. In this study, we found no significant differences in the serum levels of TNF- $\alpha$, sTNF-R1, and sTNF-R2 during migraine attack and attack-free period and no correlation between these cytokines and clinical parameters.

Other studies have also investigated TNF- $\alpha$ level during and outside migraine attacks with contradictory results. While some studies found no difference in TNF- $\alpha$ serum levels [3, 4], others described increased levels of TNF- $\alpha$ during migraine attack [5]. Regarding that TNF- $\alpha$ is an unstable molecule with a reduced half-life, several authors assess its soluble receptors as an index of TNF- $\alpha$ activity [11]. Empl et al. found decreased levels of sTNF-R1 during migraine attack, suggesting that this would result in less buffer capacity for locally released hyperalgesic TNF- $\alpha$ [12]. In contrast, we found no difference in the serum levels of sTNF-R1 and sTNF-R2 levels during migraine attacks, undermining the view of increased TNF- $\alpha$ activity during headache period. The same finding was previously reported in children with migraine attack [12]. Future studies are needed to better establish the role of TNF- $\alpha$ in the generation of migraine attack.

There is little evidence that BDNF levels are altered in migraine patients and that BDNF gene polymorphisms are related with genetic susceptibility to migraine $[8,13]$. In this study, there was an increased serum level of BDNF during migraine attack when compared to headache-free period. Besides its neurotrophic function, BDNF is a pain modulator acting in the efficiency of glutamatergic and GABAergic/glycinergic synapses [7]. Also, BDNF is in involved in the pathogenesis of migraine comorbidities 
Fig. 1 TNF, sTNF-R1, and sTNF-R2 serum levels in patients during migraine attacks and in headache-free periods
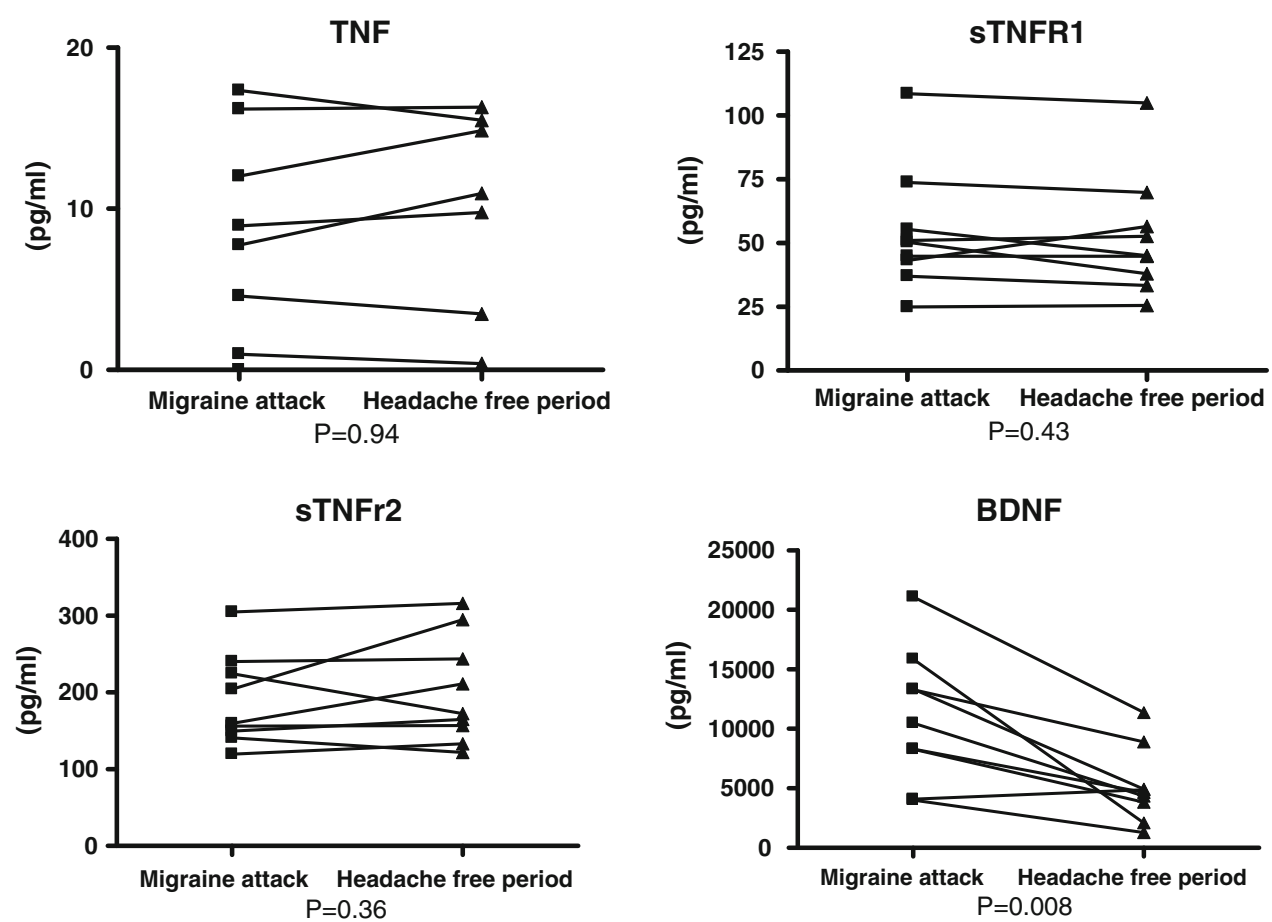

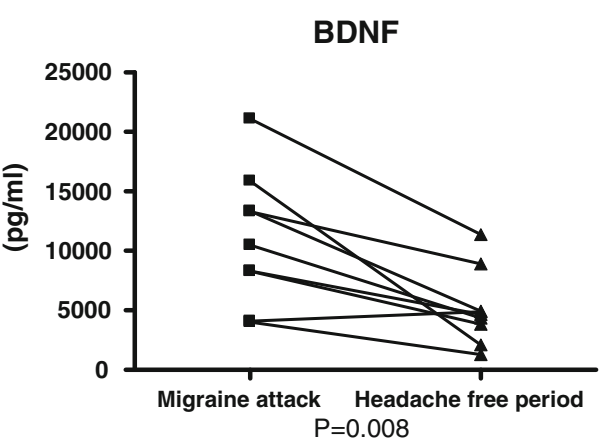

such as epilepsy and depression [14]. The precise role of BDNF in epilepsy is not fully understood but BDNF infusion has been shown to induce seizures and scavenging BDNF in vitro appears to reduce kindling development [14]. Considering that an imbalance between excitatory glutamate-mediated transmission and GABA-mediated inhibition has been postulated in migraine pathogenesis and that BDNF has been shown to modify excitability, it is possible that increased BDNF concentration may participate in the generation of migraine attack. Moreover, BDNF was recently shown to intermediate an increase of CGRP $\mathrm{P}_{2} \mathrm{X}_{3}$ receptor synthesis. The increase in the expression of $\mathrm{P}_{2} \mathrm{X}_{3}$ receptor would enhance the effect of released CGRP in triggering neurogenic inflammation [15]. Thus, BDNF is a possible mediator of trigeminal nociceptive plasticity.

This study has limitations. The number of patients is too small to be able to draw definite conclusions. There is no age matched control group. We did not the phase of menstrual cycle the female patients were when the blood was collected. These results need to be confirmed in future studies with a more conspicuous number of patients and with a more controlled definition of the time of blood sampling both during the ictal and interictal period.

To the best of our knowledge, this is the first report to show that BDNF level is increased during migraine attack and that it is inversely related with headache intensity. The relevance of BDNF in migraine is possibly related with CGRP action [15]. Currently, there are two CGRP antagonists being tested for migraine attacks in phase II and phase III studies, olcegepant and telcagepant [2, 16, 17]. It is extremely important to investigate if neurotropic factors production is influenced by the use of these new drugs. Also, future studies should evaluate these molecular mediators in different types of migraine, the effects of prophylactic therapy, and the impact of migraine comorbidities such as depression and anxiety on the levels of these mediators. A better knowledge of the relevance of molecular mediators of migraine as well as their central and peripheral actions may provide clues to the development of future new drugs directed to different targets of the migraine pathophysiologic process.

Acknowledgments This work was partly funded by Fundação de Amparo à Pesquisa do Estado de Minas Gerais (Fapemig) and by Rede Instituto Brasileiro de Neurociência (IBNet), Brazil.

\section{References}

1. Lipton RB, Stewart WF, Diamond S, Diamond SL, Reed W (2001) Prevalence and burden o migraine in the United States: data from the American Migraine Study II. Headache 41:646-657

2. Domingues RB, Teixeira AL (2009) Migrânea e Inflamação. Migrâneas cefaleias 12:126-130

3. Fidan I, Yüksel S, Ymir T, Irkeç C, Aksakal FN (2006) The importance of cytokines, chemokines and nitric oxide in pathophysiology of migraine. J Neuroimmunol 171:184-188

4. van Hilten JJ, Ferrari MD, Van der Meer JW, Gijsman HJ, Looij BJ Jr (1991) Plasma interleukin-1, tumour necrosis factor and hypothalamic-pituitary-adrenal axis responses during migraine attacks. Cephalalgia 11:65-67

5. Perini F, D’Andrea G, Galloni E, Pignatelli F, Billo G, Alba S, Bussone G, Toso V (2005) Plasma cytokine levels in migraineurs and controls. Headache 45:926-931 
6. Merighi A, Salio C, Ghirri A, Lossi L, Ferrini F, Betelli C, Bardoni R (2008) BDNF as a pain modulator. Prog Neurobiol 85:297-317

7. Blandini F, Rinaldi L, Tassorelli C, Sances G, Motta M, Samuele A, Fancellu R, Nappi G, Leon A (2006) Peripheral levels of BDNF and NGF in primary headaches. Cephalalgia 26:136142

8. Headache Classification Subcommittee of the International Headache Society (2004) The international classification of headache disorders, 2nd edn. Cephalalgia 24:1-160

9. Shin HE, Park JW, Kim YI, Lee KS (2008) Headache impact test6 (HIT-6) scores for migraine patients: their relation to disability as measured from a headache diary. J Clin Neurol 4:158-163

10. Empl M, Sostak P, Riedel M, Schwarz M, Müller N, Förderreuther S, Straube A (2003) Decreased sTNF-RI in migraine patients? Cephalalgia 23:55-58

11. Grassi-Oliveira R, Brietzke E, Pezzi JC, Lopes RP, Teixeira AL, Bauer ME (2009) Increased soluble tumor necrosis factor-alpha receptors in patients with major depressive disorder. Psychiatry Clin Neurosci 63:202-208

12. Gergont A, Kaciński M, Kwinta P (2005) Proinflammatory cytokines in children with idiopathic headache. Przegl Lek 62:1269-1275

13. Marziniak M, Herzog AL, Mössner R, Sommer C (2008) Investigation of the functional brain-derived neurotrophic factor gene variant Val66MET in migraine. J Neural Transm 115:1321-1325

14. Mattson MP (2008) Glutamate and neurotrophic factors in neuronal plasticity and disease. Ann NY Acad Sci 1144:97-112

15. Simonetti M, Giniatullin R, Fabbretti E (2008) Mechanisms mediating the enhanced gene transcription of $\mathrm{P} 2 \mathrm{X} 3$ receptor by calcitonin gene-related peptide in trigeminal sensory neurons. $\mathrm{J}$ Biol Chem 283:18743-18752

16. Farinelli I, De Filippis S, Coloprisco G, Missori S, Martelletti P (2009) Future drugs for migraine. Intern Emerg Med 4:367-373

17. Stovner LJ, Tronvik E, Hagen K (2009) New drugs for migraine. J Head Pain 10:395-406 